\title{
NOTAS SOBRE EL SISTEMA MEXICANO DE TERMINACIÓN DEL CONTRATO DE TRABAJO
}

\author{
Dr. Hugo Italo Morales SaldañA* \\ Universidad Nacional Autónoma de México
}

\section{INTRODUCCIÓN}

Todo principio de estabilidad se vulnera gravemente en la relación laboral, con la aparición de la figura del despido, considerando que el desiderátum para el derecho del trabajo es su continuidad y permanencia, hasta los límites naturales que ambas partes estén dispuestas asumir.

Partiendo de estos conceptos, calificamos como despido la ruptura del vínculo a iniciativa patronal.

En el supuesto que el trabajador acepte la decisión unilateral, sin mayor trámite y mantenga una actitud pasiva, se subsanarán todas las posibles irregularidades que pudiera tener esta conducta. En caso contrario, si existe oposición a estas medidas y por los conductos debidos reclama su aplicación ilegal solicitando la nulidad del acto y en consecuencia reincorporación o el pago de daños y perjuicios, se provoca un conflicto que las autoridades competentes deberán resolver.

Bajo el principio de estabilidad laboral, considerado como una regla general de la disciplina, las afirmaciones del trabajador se tienen por presuntivamente ciertas -salvo prueba en contrario- consecuentemente, deberá acreditarse la excepción que justifica la legalidad del despido.

En otro orden de ideas, las causales de ruptura deben estar previstas en el ordenamiento jurídico, y en su oportunidad acreditarlas fehacientemente.

Esta posición antagónica provoca la necesidad de conceder la razón a una de las partes, dando lugar a calificar la decisión patronal de ilegal o legal; en el primero de los casos se menciona la injustificación de su conducta, por haberse apartado de los principios jurídicos previstos en la legislación. En el segundo, se le otorga el reconocimiento, al advertirse que acreditó, alguna de las excepciones que fundamentan la extinción del contrato, consecuentemente del principio de permanencia.

\section{FORMALIDADES ESENCIALES}

Los sistemas jurídicos no son coincidentes en las formalidades esenciales para que la rescisión opere, en tal virtud, procederemos al estudio de cada uno de ellos:

\footnotetext{
Doctor en Derecho por la Universidad Nacional Autónoma de México. Profesor de Derecho del Trabajo en Licenciatura y Postgrado de Derecho en la misma universidad.
} 


\section{DESPIDO DIRECTO}

Cuando las disposiciones se concretan a mencionar posibilidades de rescisión, sin establecer un procedimiento concreto, nos encontramos frente al despido directo, mediante el cual el patrón simplemente comunica al trabajador su decisión al respecto y esta opera ipso jure, es decir, se ejecuta el acto separándolo en forma inmediata sin mayor trámite, dando lugar al nacimiento de una condición suspensiva, la cual se traduce en la posibilidad de resolverse en el caso de que no se reclame ante las autoridades competentes, o bien en el fallo definitivo, estas ratifican la conducta patronal

En caso contrario, la decisión unilateral se considera ilegal, calificándose al despido como injustificado, procediendo la reincorporación a las labores o en su caso al pago de daños y perjuicios, por la ruptura ilegal del contrato.

Esta postura fue asumida por la Legislación Federal del Trabajo de 1931, en cuyos postulados estableció:

"Artículo 122.- El patrón podrá rescindir la relación de trabajo".

"Artículo 123.- Si en el juicio correspondiente no comprueba el patrón la causa de la rescisión, el trabajador tendrá derecho a su elección, a que se le reinstale en el trabajo que desempeñaba o a que se le indemnice con el importe de tres meses de salario. Tendrá además derecho, cualquiera que sea la acción intentada, a que se le paguen los salarios vencidos desde la fecha del despido hasta que se cumplimente la resolución definitiva pronunciada por al Junta de Conciliación y Arbitraje".

\section{DESPIDO ESCRITO INFORMAL}

En otros casos, se exige que la decisión se dé a conocer por escrito, pero carece de trascendencia jurídica omitirla en caso de controversia, luego entonces se eleva a simple recomendación que el patrón, optativamente, lleva a cabo. La Ley Laboral de 1970 incluyó este precepto en sus disposiciones: "Artículo 46.- El trabajador o el patrón podrá rescindir en cualquier tiempo la relación de trabajo, por causa justificada, sin incurrir en responsabilidad". "Artículo 47 Fracción. XV.- El patrón deberá dar al trabajador aviso escrito de la fecha y causa o causas de la rescisión".

De la lectura anterior se advierte la inexistencia de sanción a la conducta omisiva provocando que esta disposición fuera inoperante, por inocua.

\section{DESPIDO FORMAL ESENCIAL}

En esta hipótesis el requisito de comunicación para que opere la defensa patronal es de tal manera formal, que su omisión supone ilicitud en la conducta; las posibilidades pueden ser varias, a saber:

\subsection{PRIMERA SITUACIÓN}

Se omite la comunicación escrita, pero es admisible otro medio de prueba para demostrar que se hizo de conocimiento del trabajador el despido; es decir, se le dan a conocer 
verbalmente las razones o sinrazones de la rescisión y este tuvo conocimiento de sus efectos y causas.

\subsection{SEgUndA SITUACIÓN}

Se omite la comunicación escrita, y en el Cuerpo Jurídico no se establece ningún medio alterno análogo; en consecuencia esta violación provoca necesariamente la calificación de ilegal sin prueba en contrario.

La hipótesis está prevista en la Legislación vigente a partir de las reformas procesales de 1980:

"Artículo 47.- son causas de rescisión de la relación de trabajo sin responsabilidad para el patrón (...)”.

FRACC. XV.- "El patrón deberá dar al trabajador aviso escrito de la fecha y causa o causas de la rescisión.

El aviso deberá hacerse del conocimiento del trabajador, y en caso de que éste se negare a recibirlo, el patrón dentro de los cinco días siguientes a la fecha de la rescisión, deberá hacerlo del conocimiento de la Junta respectiva, proporcionando a ésta el domicilio que tenga registrado y solicitando su notificación al trabajador.

La falta de aviso al trabajador o a la Junta, por sí solo bastará para considerar que el despido fue injustificado" (las cursivas son nuestras).

\section{DESPIDO CONTRACTUAL}

Las partes que suscriben el contrato colectivo, exigen mayores formalidades para que el despido opere: Vg. a) autorización previa del sindicato; b) acta administrativa con la presencia sindical; c) rigorismo en las causales de despido, etc.

\section{DESPIDO PROPUESTO}

Se requieren múltiples condiciones para su cumplimiento; independientemente del acta administrativa, a la cual debe comparecer la parte afectada, se exige además la presencia de su representante o asesor jurídico; testigos de cargo, descargo y asistencia, así como un señalamiento concreto de los actos que se imputan, respetando las garantías de audiencia y legalidad, permitiendo inclusive ofrecimiento y desahogo de pruebas. Una vez concluidas estas formalidades, el patrón deberá concurrir al Tribunal competente, demandando la rescisión del vínculo jurídico, sin la posibilidad de separación previa.

Excepcionalmente procede la suspensión durante el desarrollo del proceso en la vía incidental, siempre y cuando a juicio del sindicato o las autoridades, las causas que se imputan sean de naturaleza grave y que justifica la petición, o bien en los casos en que el trabajador maneje el dinero de la empresa o institución.

Los artículos 46 (in fine) y 46 bis de la Ley Federal de los Trabajadores al Servicio del Estado, lo mencionan en los siguientes términos: 
Artículo 46 (in fine) (...) Por cualquiera de las causas a que se refiere está fracción, el Titular de la Dependencia podrá suspender los efectos del nombramiento, si con ello está conforme el Sindicato correspondiente; pero si éste no estuviere de acuerdo y cuando se trate de alguna de las causas graves previstas en los incisos a), c), e) y h), el titular podrá demandar la conclusión de los efectos del nombramiento ante el Tribunal Federal de Conciliación y Arbitraje, el cual proveerá de plano, el incidente por separado, la suspensión de los efectos de nombramiento, sin perjuicio de continuar el procedimiento en lo principal hasta agotarlo en los términos y plazos que correspondan, para determinar en definitiva sobre la procedencia o improcedencia de la terminación de los efectos del nombramiento.

Cuando el Tribunal resuelva que procede dar por terminados los efectos del nombramiento sin responsabilidad para el Estado, el trabajador no tendrá derecho al pago de salarios caídos".

"Artículo 46 bis.- Cuando el trabajador incurra en alguna de las causales a que se refiere la fracción $\mathrm{V}$ del artículo anterior, el jefe superior de la oficina procederá a levantar acta administrativa, con intervención del trabajador y un representante del sindicato respectivo, en la que con toda precisión se asentarán los hechos, la declaración del trabajador afectado y las de los testigos de cargo y descargo que se propongan, la que se firmara por los que en ella intervengan y por dos testigos de asistencia, debiendo entregar en ese mismo acto, una copia al trabajador y otra al representante sindical.

Si a juicio del Titular procede demandar ante el Tribunal Federal de Conciliación y Arbitraje la terminación de los efectos del nombramiento del trabajador, a la demanda se acompañarán, como instrumentos base de la acción, el acta administrativa y los documentos que, al formularse ésta, se hayan agregado a la misma".

El derecho laboral burocrático menciona diversas expresiones aplicables a la extinción del vínculo (terminación; remoción; destitución, etc.). La terminología es muy densa y se presta a confusiones. Este vocabulario propio del derecho administrativo, ha impedido la independencia disciplinaria, la cual se traduce en múltiples irregularidades que se derivan de sus alcances, interpretación y ubicación dentro de la sistemática jurídica.

Los vocablos que utiliza la doctrina y legislación laboral, para referirse a las formas de concluir la relación son: "terminación” y "rescisión”. El primero implica una conclusión por voluntad de las partes o motivos ajenos, sin responsabilidad posterior.

En el segundo caso implica una ruptura unilateral que se califica de justificada o injustificada, cuando proviene del patrón, y separación, cuando la conducta es realizada por el trabajador.

\section{PREAVISO}

Se establece como requisito formal para que opere el despido, un aviso previo que conceda la oportunidad al afectado de buscar trabajo. La omisión de esta formalidad provoca diversas consecuencias. 
El preaviso opera en nuestro medio contractualmente, por tal motivo depende del acuerdo de voluntades, como resultado de esta práctica su incumplimiento se puede traducir en conducta irregular, cuando se omite; ocasionalmente -si existe consentimiento de voluntades- en el pago en efectivo del plazo pendiente o considerar injustificado el despido, por el incumplimiento de una obligación esencial.

\section{DESPIDOS INDIRECTOS}

Existen múltiples figuras laborales que sin calificarse propiamente de despidos, su aplicación se traduce en las mismas consecuencias -pérdida del empleo-; procederemos a su estudio.

a) Rescisión del trabajador (separación imputable al patrón). En estos casos, es el propio afectado quien decide dar por concluida la relación, atribuyéndole a su contraparte violaciones graves que hacen imposible la continuación del servicio, procediendo a su extinción unilateral en la cual se califica de justificada o injustificada por el Tribunal cuando se somete a su consideración, dando lugar con su fallo al pago de daños y perjuicios, en caso de declararse procedente; por razones obvias, el ejercicio de la acción solo puede apoyarse en conceptos indemnizatorios y jamás en reinstalación, puesto que su reincorporación rayaría en lo absurdo, destacándose así la diferencia con el despido patronal que genera la posibilidad de dos solicitudes alternativas: cumplimiento de contrato o indemnización.

“Artículo 50. Las indemnizaciones a que se refiere el artículo anterior consistirán:

I. Si la relación de trabajo fuere por tiempo determinado menor de un año, en una cantidad igual al importe de los salarios de la mitad del tiempo de servicios prestados; si excediera de un año, en una cantidad igual al importe de los salarios de seis meses por el primer año y de veinte días por cada uno de los años siguientes en que hubiese prestado sus servicios;

II. Si la relación de trabajo fuere por tiempo indeterminado, la indemnización consistirá en veinte días de salario por cada uno de los años de servicios prestados; y

III. Además de las indemnizaciones a que se refieren las fracciones anteriores, en el importe de tres meses de salario y en el de los salarios vencidos desde la fecha del despido hasta que se paguen las indemnizaciones".

"Artículo 51. Son causas de rescisión de la relación de trabajo, sin responsabilidad para el trabajador:

I. Engañarlo el patrón o, en su caso, la agrupación patronal al proponerle el trabajo, respecto de las condiciones del mismo. Esta causa de rescisión dejará de tener efecto después de treinta días de prestar sus servicios el trabajador;

II. Incurrir el patrón, sus familiares o su personal directivo o administrativo, dentro del servicio, en faltas de probidad u honradez, actos de violencia, o amenazas, injurias, malos tratamientos y otros análogos, en contra del trabajador, cónyuge, padres, hijos o hermanos; 
III. Incurrir el patrón, sus familiares o trabajadores, fuera del servicio, en los actos a que se refiere la fracción anterior, si son de tal manera graves que hagan imposible el cumplimiento de la relación de trabajo;

IV. Reducir el patrón el salario del trabajador;

V. No recibir el salario correspondiente en la fecha o lugar convenidos o acostumbrados;

VI. Sufrir perjuicios causados maliciosamente por el patrón, en sus herramientas o útiles de trabajo;

VII La existencia de un peligro grave para la seguridad o salud del trabajador o de su familia, ya sea por carecer de condiciones higiénicas el establecimiento o porque no se cumplan las medidas preventivas y de seguridad que las leyes establezcan;

VIII. Comprometer el patrón, con su imprudencia o descuido inexcusables, la seguridad del establecimiento o de las personas que se encuentren en él; y

IX. Las análogas a las establecidas en las fracciones anteriores, de igual manera graves y de consecuencias semejantes, en lo que al trabajador se refiere".

"Artículo 52. El trabajador podrá separarse de su trabajo dentro de los treinta días siguientes a la fecha en que se dé cualquiera de las causas mencionadas en el artículo anterior y tendrá derecho a que el patrón lo indemnice en los términos del artículo 50”.

b) Exclusión por separación: por su naturaleza contractual este supuesto se aplica en los casos en los cuales empresa y sindicato incluyen en la contratación colectiva, los extremos previstos en la Ley Federal del Trabajo

“Artículo 395. En el contrato colectivo podrá establecerse que el patrón admitirá exclusivamente como trabajadores a quienes sean miembros del sindicato contratante. Esta cláusula y cualesquiera otra que establezcan privilegios en su favor, no podrán aplicarse en perjuicio de los trabajadores que no formen parte del sindicato y que ya presenten sus servicios en la empresa o establecimiento con anterioridad a la fecha en que el sindicato solicite la celebración o revisión del contrato colectivo y la inclusión en él de la cláusula de exclusión.

Podrá también establecerse que el patrón separará del trabajo a los miembros que renuncien o sean expulsados del sindicato contratante".

La naturaleza indirecta del despido se destaca con toda claridad en el texto del precepto, puesto que la separación del trabajador opera cuando deja de tener carácter de sindicalizado - por renuncia o expulsión- y el organismo obrero solicita su retiro por haber perdido la calidad de agremiado, la cual constituye la hipótesis fundamental (permanencia en el sindicato).

La hipótesis que se concretiza en el acto contractual, es discutible en su constitucionalidad, puesto que los derechos y obligaciones surgidos del vínculo entre las partes, pueden estar cumpliéndose sin existir causas de ruptura, sin embargo las obligaciones contraídas con el organismo obrero, exigen su cumplimiento en la forma descrita. Esta disposición jurídica poco a poco pierde efectos y la propia Corte, en Jurisprudencia, determinó su inconstitucio- 
nalidad, sin embargo, sus efectos al no ser extensiva a todos, motiva que su práctica continúe desarrollándose, pero en contra de un criterio definido del máximo tribunal.

En caso de improcedencia en su aplicación, provoca que el sindicato sea condenado a reinstalación, salarios caídos, y el patrón a reintegrar a sus labores al afectado, calificándose en consecuencia de dichas medidas como figura similar al despido y con idénticas consecuencias.

\section{TERMINACIÓN COLECTIVA}

Esta figura, cuyas posibilidades son múltiples, en la mayoría de los casos se traduce en el pago de indemnizaciones, no obstante apegarse a las formalidades jurídicas.

"Artículo 433. La terminación de las relaciones de trabajo como consecuencia del cierre de las empresas o establecimientos o de la reducción definitiva de su trabajo, se sujetará a las disposiciones de los artículos siguientes".

“Artículo 434. Son causas de terminación de las relaciones de trabajo:

I.- La fuerza mayor o el caso fortuito no imputable al patrón, o su incapacidad física o mental o su muerte, que produzca como consecuencia necesaria, inmediata y directa, la terminación de los trabajos;

II.- La incosteabilidad notoria y manifiesta de la explotación;

III.- El agotamiento de la materia objeto de una industria extractiva;

IV.- Los casos del artículo 38; y

V.- $\quad$ El concurso o la quiebra legalmente declarado si la autoridad competente o los acreedores resuelven el cierre definitivo de la empresa o la reducción definitiva de sus trabajos".

"Artículo 435. En los casos señalados en el artículo anterior, se observarán las normas siguientes:

I.- $\quad$ Si se trata de las fracciones I y V, se dará aviso de la terminación a la Junta de Conciliación y Arbitraje, para que ésta, previo el procedimiento y consignado en el artículo 782 y siguientes, la apruebe o desapruebe;

II.- $\quad$ Si se trata de la fracción III, el patrón previamente a la terminación, deberá obtener la autorización de la Junta de Conciliación y Arbitraje, de conformidad con las disposiciones contenidas en el artículo 782 y siguientes; y

El patrón, previamente a la terminación, deberá obtener la autorización de la Junta de Conciliación y Arbitraje, de conformidad con las disposiciones para conflictos colectivos de naturaleza económica”.

"Artículo 436. En los casos de terminación de los trabajos señalados en el artículo 434, salvo el de la fracción IV, los trabajadores tendrán derecho a una indemnización de tres meses de salario, y a recibir la prima de antigüedad a que se refiere el artículo 162”. 
"Artículo 437. Cuando se trate de reducción de los trabajos en una empresa o establecimiento, se tomará en consideración el escalafón de los trabajadores, a efecto de que sean reajustados los de menor antigüedad".

"Artículo 438. Si el patrón reanuda las actividades de su empresa o crea una semejante, tendrá las obligaciones señaladas en el artículo 154.

Lo dispuesto en el párrafo anterior es aplicable, en el caso de que se reanuden los trabajos de la empresa declarada en estado de ocurso o quiebra”.

"Artículo 439. Cuando se trate de la implantación de maquinaria o de procedimientos de trabajo nuevos, que traiga como consecuencia la reducción de personal, a falta de convenio, el patrón deberá obtener la autorización de la Junta de Conciliación y Arbitraje, de conformidad con los dispuesto en el artículo 782 y siguientes. Los trabajadores reajustados tendrán derecho a una indemnización de cuatro meses de salario, más veinte días por cada año de servicios prestados o la cantidad estipulada en los contratos de trabajo si fuese mayor y a la prima de antigüedad a que se refiere el artículo $162 "$.

\section{CONSECUENCIAS DEL DESPIDO}

Desde el nacimiento de la Carta Fundamental, se estableció la opción del trabajador para reclamar indemnización o su readmisión en caso de injustificado despido. Luego entonces, las consecuencias laborales de estas medidas patronales que le afectan no tienen la menor duda interpretativa, sin embargo, existen varios aspectos constitucionales que repercuten en los despidos y pudieran vulnerar sus alcances y consecuencias, son a saber: la negativa a reinstalar y la insumisión al arbitraje o laudo.

Las múltiples interpretaciones del citado precepto solo han provocado confusiones en lugar de avances.

a) Negativa a reinstalar: con motivo de las reformas al artículo 123 fracción XXI de la Carta Magna, el texto correspondiente quedó redactado en la siguiente forma:

"Artículo 123 FRACC. XXI. Si el patrono se negare a someter sus diferencias al arbitraje o a aceptar el laudo pronunciado por la Junta, se dará por terminado el contrato de trabajo y quedará obligado a indemnizar al obrero con el importe de tres meses de salario, además de la responsabilidad que le resulte del conflicto. Esta disposición no será aplicable en los casos de las acciones consignadas en la fracción siguiente. Si la negativa fuere de los trabajadores, se dará por terminado el contrato de trabajo";

FRACC. XXII. El patrono que despida a un obrero sin causa justificada o por haber ingresado a una asociación o sindicato, o por haber tomado parte en una huelga lícita, estará obligado, a elección del trabajador, a cumplir el contrato o a indemnizarlo con el importe de tres meses de salario. La ley determinará los casos en que el patrono 
podrá ser eximido de la obligación de cumplir el contrato mediante el pago de una indemnización. Igualmente tendrá la obligación de indemnizar al trabajador con el importe de tres meses de salario cuando se retire del servicio por falta de probidad del patrono o por recibir de él malos tratamientos, ya sea en su persona o en la de su cónyuge, padre, hijo o hermanos. El patrono no podrá eximirse de esta responsabilidad cuando los malos tratamientos provengan de dependientes o familiares que obren con el consentimiento o tolerancia de él”.

La Ley Federal del Trabajo anterior reglamentó sus alcances así:

"Artículo 123. Si en el juicio correspondiente no comprueba el patrón la causa de la rescisión, el trabajador tendrá derecho, a su elección, a que se le reinstale en el trabajo que desempeñaba o a que se le indemnice con el importe de tres meses de salario.

Tendrá, además, derecho, cualquiera que sea la acción intentada, a que se le paguen los salarios vencidos desde la fecha del despido hasta que se cumplimente la resolución definitiva pronunciada por la Junta de Conciliación y Arbitraje".

"Artículo 124. El patrón quedará eximido de la obligación de reinstalar al trabajador, mediante el pago de las indemnizaciones que se determinen en el artículo siguiente:

I. Cuando se trate de trabajadores que tengan una antigüedad menor de dos años.

II. Si comprueba ante la Junta de Conciliación y Arbitraje que el trabajador, por razón del trabajo que desempeña o por las características de sus labores, está en contacto directo y permanente con él y la Junta estima, tomando en consideración las circunstancias del caso, que no es posible el desarrollo normal de la relación de trabajo.

III. En los casos de aprendices.

IV. En los casos de los empleados de confianza.

V. En el servicio doméstico.

VI. Cuando se trate de trabajadores eventuales".

“Artículo 125. Las indemnizaciones a que se refiere el artículo anterior consistirán:

I. En el importe de tres meses de salario;

II. Si la relación de trabajo fuere por tiempo determinado, y éste no excediere de un año, en una cantidad igual al importe de los salarios de la mitad del tiempo de servicios prestados; si el término excediere de un año, en una cantidad igual al importe de los salarios de seis meses por el primer año y de veinte días por cada uno de los años siguientes en que hubiere prestado sus servicios. Si la relación de trabajo fuere por tiempo indeterminado la indemnización consistiría en veinte días de salario por cada uno los años de servicios prestados.

III. En el importe de los salarios vencidos desde la fecha del despido hasta que se paguen las indemnizaciones a que se refieren las dos fracciones anteriores". 
De la lectura mencionada se llega a la conclusión de que las reformas transcritas dieron lugar a una estabilidad relativa, toda vez que no en todos los casos de separación injustificada se obligaba al patrón al cumplimiento de la conducta omitida, es decir, a la reinstalación forzosa.

Por considerarlo de interés para nuestro estudio, a continuación analizaremos las excepciones a que se refiere el precepto anterior y expondremos nuestros puntos de vista en relación con su procedencia.

b) Temporales: se establece la posibilidad de sustituir la reinstalación cuando no se han cumplido dos años de servicio.

Se consideró que dicho lapso era suficiente para que las partes se acostumbraran a los sistemas y métodos de trabajo, y que la separación antes de dicho plazo no producía consecuencias graves. Nuestro legislador adaptó esta situación de la legislación brasileña, en la que se exigen diez años de servicios efectivos, para que se aplique el régimen.

Es plausible la intención contenida en los preceptos de la Ley Federal del Trabajo, ya que el tiempo establecido es sumamente corto y, por ende, se justifica la excepción. La legislación laboral actual redujo el término a un año, en beneficio del trabajador.

c) Contacto permanente: no estamos de acuerdo con esta excepción, puesto que su ambigüedad y falta de claridad provoca confusiones. Debió establecerse con mayor precisión ya que se abstienen de distinguir el contacto directo y permanente con las personas físicas o morales.

En el primero de los casos, es fácil para el empleador demostrar la existencia de relaciones entre las partes, que impiden el desarrollo normal del servicio, ya que siempre existe un contacto directo y permanente.

Tratándose de personas morales, esta circunstancia no puede demostrarse, a menos que se equipare la representación patronal responsable de la separación injustificada, con el patrón mismo. No obstante, en este caso también es difícil para el patrón probar la imposibilidad de reanudación del trabajo en condiciones normales, salvo que el juzgador interprete la ley con demasiada amplitud. Y considere que al que despidió, solo por su carácter de representante patronal, le es aplicable la excepción.

Cabe señalar, sin embargo, que a los patrones se les otorga una puerta falsa para negarse a la reinstalación obligatoria, ya que la amplitud que se le puede otorgar al precepto, hace nugatorio el derecho de los trabajadores, puesto que al encontrarse legal en todo lo concerniente al trabajo, es indiscutible que puede caracterizarse la excepción.

d) Aprendices: dicho precepto los incluyó injustificadamente. La Legislación derogada en su artículo 226, descartaba toda posibilidad de reanudación de servicios en los siguientes términos: "Artículo 226. El aprendiz puede justificadamente separarse del trabajo por violación de las obligaciones que impone al patrón o maestro el artículo 224".

En este caso, y en el despido sin causa justificada, el aprendiz tenía derecho a un mes y medio de indemnización. No hay que olvidar que el contrato de aprendiz se equiparaba al de trabajo, pero no se identificaban ambos; en esa virtud, el primero se regía por los princi- 
pios específicos de acuerdo con la naturaleza del contrato; prueba de lo anterior, es que en su calidad de aprendiz no tenía derecho al salario mínimo, circunstancia que no advertimos jamás en el vínculo laboral.

A mayor abundamiento, la obligación fundamental del patrón consistía en enseñar y jamás en retribuir; por lo tanto, en momento alguno se podría obligar a este a prestar enseñanza, ya que se violaría en su principio, la garantía individual consignada en el artículo $5^{\circ}$ constitucional. Por lo tanto, ante la imposibilidad de ejercitar esta acción, se transforma en una de daños y perjuicios, que nuestra propia ley reglamentaria cuantifica en mes y medio de indemnización.

Por las razones anteriormente expuestas, pensamos que no se estudió debidamente el caso especialísimo de los aprendices. Sin embargo, cabe mencionar que esta excepción ha dejado de tener interés, ya que la codificación laboral vigente eliminó el contrato de aprendizaje.

e) Personal de confianza: es tan ambiguo el término, que solo debe desprenderse de la lectura de los artículos 48 y 126 fracción X de la Ley Federal del Trabajo anterior, en relación con el $9^{\circ}, 184$ y 185 de la actual.

"Artículo 48.- Las estipulaciones del contrato colectivo se extienden a todas las personas que trabajan en la empresa, aunque no sean miembros del sindicato que lo haya celebrado. Se puede exceptuar de esta disposición a las personas que desempeñen puestos de dirección y de inspección de las labores, así como a los empleados de confianza en trabajos personales del patrón, dentro de la empresa”.

"Artículo 126.- El contrato de trabajo terminará:

Fracción X.- Por perder la confianza del patrón, el trabajador que desempeñe un empleo de dirección, fiscalización o vigilancia; más si había promovido, de un puesto de escalafón en las empresas en que éste existe, volverá a él, salvo que haya motivo justificado para su despido. Lo mismo se observará cuando el trabajador que desempeña un puesto de confianza, solicite volver a su antiguo empleo".

"Artículo $9^{\circ}$.- La categoría de trabajador de confianza depende de la naturaleza de las funciones desempeñadas y no de la designación que se dé al puesto.

Son funciones de confianza las de dirección, inspección, vigilancia y fiscalización, cuando tengan carácter general, y las que se relacionen con trabajos personales del patrón, dentro de la empresa o establecimiento".

"Artículo 184.- Las condiciones de trabajo contenidas en el contrato colectivo que rija en la empresa o establecimiento se extenderán a los trabajadores de confianza, salvo disposición en contrario consignada en el mismo contrato colectivo".

"Artículo 185.- El patrón podrá rescindir la relación de trabajo si existe un motivo razonable de pérdida de la confianza, aun cuando no coincida con las causas justificadas de rescisión a que se refiere el artículo 47. 
El trabajador de confianza podrá ejercitar las acciones a que se refiere el capítulo IV del título segundo de esta ley".

De la lectura de los preceptos anteriores se pueden deducir las características que normalmente tienen los empleados de confianza, es decir, sustituyen al patrón total o parcialmente en las funciones que a este le corresponden; o bien, colaboran con él en un contacto íntimo, llevando a cabo trabajos personales, razón por la cual también pueden ser de confianza, sin sustituirle en su actividades.

Sin embargo, debemos advertir que no basta ponerse de acuerdo en la celebración del contrato colectivo determinando quiénes son los empleados de confianza, para que el juzgador les otorgue esta naturaleza. Es indispensable demostrar la existencia de una relación subjetiva entre las partes y que precisamente haya sido la razón de su contratación. El trabajador debe haberse vinculado especialmente para el desempeño de una función, que en esencia corresponda a su patrón, lo cual permite otorgarle la denominación de "confianza".

No nos oponemos a la excepción; por el contrario, la aceptamos: pero hemos de advertir que la carga de la prueba respecto de la calidad del trabajador, corresponde al patrón y es muy difícil de demostrar.

f) Servicio doméstico: no es un trabajador ordinario; se le equipara a un familiar, por tal razón se le otorga un trato distinto y excepcional respecto de cualquier otro asalariado. En esa virtud, atentaría contra la familia el que se le impusiera convivir con esta clase de personal en contra de la voluntad patronal.

g) Eventuales: es demasiado vago el concepto, en ninguna disposición laboral se le menciona; sin embargo, consideramos que se refiere a los trabajadores no permanentes.

No estamos de acuerdo con esta excepción, ya que pugna con los principios fundamentales del derecho mexicano del trabajo. La exposición de motivos nos parece inconsistente, hubiera sido más conveniente aceptar su reinstalación, si en el momento de la ejecución del fallo subsistieran las causas que originaron la contratación.

Solamente en el caso de no existir, la posibilidad física de cumplimiento, admitiríamos la sustitución, por el pago de daños y perjuicios.

\section{INSOMETIMIENTO AL ARBITRAJE}

Otro de los casos de terminación de la relación de trabajo es precisamente el insometimiento al arbitraje, consignado en los artículos 947 y 948 de la Ley vigente al indicar:

"Artículo 947.- Si el patrón se negare a someter sus diferencias al arbitraje o a aceptar el laudo pronunciado, la junta:

I. Dará por terminada la relación de trabajo;

II. Condenará a indemnizar al trabajador con el importe de tres meses de salario; 
III. Procederá fijar la responsabilidad que resulte al patrón del conflicto, de conformidad con lo dispuesto en el artículo 50, fracciones I y II; y

IV. Además, condenará al pago de los salarios vencidos desde la fecha en que dejaron de pagarlos hasta que se paguen las indemnizaciones, así como al pago de la prima de antigüedad, en los términos del artículo 162".

Las disposiciones contenidas en este artículo no son aplicables en los casos de las acciones señaladas en el artículo 123 fracción XXII, apartado "A” de la Constitución”

"Artículo 948. Si la negativa a aceptar el laudo pronunciado por la Junta fuere de los trabajadores se dará por terminada la relación de trabajo, de conformidad con los dispuesto por el artículo 519 fracción III, último párrafo de esta ley”.

Los preceptos anteriores frecuentemente se confunden con los artículos 50 y 51 de la legislación ordinaria -transcritos con anterioridad-, toda vez que provienen de la misma fracción XXI del 123 apartado "A" Constitucional; sin embargo, existen diferencias fundamentales.

La negativa para acatar un laudo o someterse al arbitraje, tuvo sus orígenes históricos en los deseos legislativos de concretar la función de la autoridad laboral a solucionar problemas económicos colectivos; de acuerdo con dicha hipótesis, las Juntas no tenían carácter jurisdiccional, puesto que no podía obligarse al patrón a un cambio de condiciones económicas en contra de su voluntad, pero su rebeldía se sancionaba con una indemnización.

Desde el momento en que las Juntas de Conciliación y Arbitraje se encontraron en posibilidad de resolver toda clase de conflictos, inclusive los jurídicos, el precepto constitucional originó confusiones.

Basta pensar que en el caso de reclamarse indemnización por riesgo profesional, resultaba absurdo que con una simple negativa al arbitraje se cubrieran tres meses de salario y resultara así un pago muy inferior al de la obligación legal. Los abusos cometidos en casos de reinstalación, también se multiplicaron durante todo el período anterior a las reformas.

Cabe concluir, por lo tanto, que los conflictos jurídicos no se rigen por este precepto, ya que las partes no pueden sustraerse a la jurisdicción laboral y la excepción a que se alude en los artículos 49 y 50, no tiene punto de identificación con el sometimiento a la Junta o negativa de cumplimiento al fallo; basta un análisis meticuloso de la parte relativa para llegar a esta conclusión.

El primer numeral indica: "Artículo 49. El patrón quedará eximido de la obligación de reinstalar al trabajador (...)"

Luego entonces, solo la autoridad juzgadora podrá eximirlo de reinstalar, lo que hace suponer que las partes se sometieron al tribunal y que al dictarse laudo condenatorio, la demandada invocó una causal de excepción; en caso de aceptarse bajo ese calificativo, le permite sustituir el cumplimiento del fallo por el pago de las cantidades previstas por la propia legislación.

Resulta un error invocar la excepción al iniciarse el proceso o durante su desarrollo, puesto que la hipótesis está condicionada al laudo condenatorio. 
Algunas autoridades afirman que es preferible invocar desde un principio la circunstancia eximente para evitar pérdida de tiempo, lo cual demuestra una ignorancia absoluta en la aplicación normativa, puesto que la claridad del precepto no admite diversas interpretaciones, debe considerarse que donde la ley no distingue no debemos distinguir

En todo caso, el patrón que de antemano acepta cubrir la prestación en efectivo, para ser congruente con la disposición, debe allanarse a la reclamación, haciendo notar a la Junta que al dictarse laudo condenatorio, acreditará en el incidente la negativa a reinstalar y en esta forma se colocará dentro de la hipótesis prevista.

\section{LEGISLACIÓN INTERNACIONAL}

En el año de 1982, la O.I.T. adoptó un Convenio Internacional relativo al tema, denominado "Terminación de la relación de trabajo por iniciativa del empleador", dicho instrumento establece en sus principios fundamentales:

a) Los principios de estabilidad solo son aplicables a contratos indefinidos.

b) La terminación solo procede por motivos de capacidad, conducta o necesidades de funcionamiento de la empresa.

c) No constituye causa justificada: sindicalización, representación sindical, quejas contra el patrón, discriminación por cualquier causa o maternidad.

d) Siempre podrá recurrirse a un organismo competente para impugnar el despido.

e) La carga de la prueba para demostrar el despido siempre será del empleador.

f) De no ser recomendable la reinstalación, será sustituida por una indemnización razonable.

g) Deberá existir preaviso o indemnización por omitirlo, salvo en los casos de justificación.

h) Razones tecnológicas, económicas, estructurales o análogas deberán ser consultadas previamente con los organismos obreros y autoridades laborales, las que tomarán las medidas que indique la legislación nacional.

Como es la costumbre de dicho organismo, se adoptó una recomendación similar aplicable a todos los que no ratificaron el Convenio. Las disposiciones internacionales indican que en estos casos el país miembro deberá informar periódicamente las prácticas laborales que coinciden con la recomendación, y los motivos que apoyan su decisión para no ratificar la Convención.

México se encuentra en esta última hipótesis, sin embargo, cumple íntegramente con todas las partes del Convenio, y con posibilidades de ratificación futura sin problema alguno.

\section{JUBILACIÓN}

Este concepto se encuentra previsto en el artículo 123 de la Legislación Constitucional de Trabajo Mexicana, en el apartado "A" fracción XXIX y apartado "B" fracción XI inciso c), en los siguientes términos: 
Artículo 123 Apartado "A” Fracción XXIX.- Es de utilidad pública la Ley del Seguro Social, y ella comprenderá seguros de invalidez, de vejez, de vida, de cesación involuntaria del trabajo, de enfermedades y accidentes, de servicios de guardería y cualquier otro encaminado a la protección y bienestar de los trabajadores, campesinos, no asalariados y otros sectores sociales y sus familiares;

"Apartado "B" Fracción XI.- La seguridad social se organizará conforme a las siguientes bases mínimas: c) Las mujeres durante el embarazo no realizarán trabajos que exijan un esfuerzo considerable y signifiquen un peligro para su salud en relación con la gestación; gozarán forzosamente de un mes de descanso antes de la fecha fijada aproximadamente para el parto y de otros dos después del mismo, debiendo percibir su salario íntegro, conservar su empleo y los derechos que hubieren adquirido por la relación de trabajo. En el período de lactancia tendrán dos descansos extraordinarios por día, de media hora cada uno, para alimentar a sus hijos. Además disfrutarán de asistencia médica y obstétrica, de medicinas, de ayudas para la lactancia y del servicio de guarderías infantiles".

La Suprema Corte de Justicia de la Nación, en múltiples resoluciones, afirma que es un figura contractual y debe estarse a los alcances de la voluntad de las partes, lo cual definitivamente se aleja de la realidad toda vez que -como quedó demostrado- la seguridad social mexicana se menciona en diversos ordenamientos federales y locales.

Lo anterior, independientemente que muchas contrataciones colectivas vigentes superen los conceptos legales, mejorando sus alcances y otorgando prestaciones complementarias superiores a las establecidas en la norma.

La jubilación constituye en todos los casos un motivo de extinción de la relación laboral; precisamente por esa razón, las instituciones públicas exigen al interesado una carta de renuncia en sus labores en caso de estar prestando servicios durante el trámite. A mayor abundamiento, algunas empresas al cumplirse la condición para jubilarse entregan al trabajador con su renuncia una liquidación cuyos montos se asimilan a las cantidades que se cubren por despido injustificado -independientemente de la jubilación-.

Estas medidas han provocado confusiones en las interpretaciones de los tribunales, y en algunos casos han exigido a la empresa su pago, no obstante no encontrarse acordado entre las partes.

Sin embargo, lo más importante para nuestro estudio es demostrar que la jubilación constituye una causa más de la extinción laboral, y con consecuencias asimilables al despido en algunos casos.

\section{CONCLUSIONES FINALES}

El despido constituye una ruptura contractual, que afecta el desarrollo normal del servicio.

Por sus propias características, el motivo que provoca esta medida puede tener fundamento jurídico, en tal caso lo calificamos de justificado y sin responsabilidad patronal. 
En situación contraria se considera injustificado, por lo tanto implica diversas consecuencias al empleador. Generalmente se le otorgan al trabajador dos opciones para reclamar ante los tribunales: a) reinstalación y salarios caídos, b) cumplimiento de contrato y salarios caídos.

En situaciones excepcionales enunciadas expresamente, la regla general puede sustituir la obligación de reinstalar por el pago de sumas concretas previstas en la legislación.

El caso anterior no debe confundirse con la insumisión al arbitraje o al laudo, toda vez que son figuras diversas.

En efecto, la posibilidad de no concurrir a la autoridad laboral en defensa de los derechos, o rechazar su fallo, constituye un dato histórico incluido en la Constitución, cuando se crearon las juntas como órganos administrativos para la atención de asuntos colectivos.

Múltiples figuras laborales distintas al despido, asimilan las mismas consecuencias, vg.: terminación, separación, remoción, destitución, reajuste, jubilación, etc.

En el derecho laboral universal, el despido constituye el mayor porcentaje de conflictos ante los tribunales, y por su naturaleza obrero-patronal, frecuentemente se define esta disciplina considerándola como el único objeto de su creación, lo cual es grave error.

A mayor abundamiento, los principios generales de derecho se inspiran en esta figura en sus diversas expresiones.

La estabilidad de las relaciones laborales es un paradigma, toda vez que la extinción del vínculo entre las partes durante su período de vigencia constituye una práctica ordinaria.

Debemos propugnar por una mayor estabilidad en las relaciones laborales. Las consecuencias de todo despido bajo cualquiera de sus figuras, provoca el desempleo, en detrimento de la economía familiar y su armonía interna, alcanzando puntos de gravedad cuando tiene el carácter de masivo, dando lugar que gravite sobre aspectos sociales del Estado, que ponen en peligro su propio equilibrio político. 